\title{
Dynamic Analysis of a Cable-Stayed Deck Steel Arch Bridge
}

\author{
P. Galvín, J. Domínguez* \\ Escuela Superior de Ingenieros, Universidad de Sevilla, Camino de los \\ Descubrimientos s/n, 41092 Sevilla, Spain
}

\begin{abstract}
A theoretical and experimental research work in relation to Barqueta cable-stayed bridge is described in this paper. Barqueta Bridge, across Guadalquivir river, links the city of Seville with the Scientific Park Cartuja 93. At jam hours cars may cover one half of the bridge lanes for more than one hour. Full-scale tests were carried out to measure the bridge dynamic response. The experimental program included the dynamic study for two different live load conditions: the bridge with one half of it lanes full of cars, and the bridge empty of cars. Modal parameters estimations were made based on the acquired data. Ten vibration modes were identified in the frequency range of $0-6 \mathrm{~Hz}$ by different techniques, being two of these modes very close to each other. The traffic-structure interaction is also studied. Experimental results were compared with those obtained from a three-dimensional finite element model developed in this work. Both sets of results show very good agreement. Finally, a damage identification technique has been applied to determine the integrity of the structure. Results obtained from a test developed in July 2005 have been correlated to experimental results obtained in October 2006 using the damage index method.
\end{abstract}

Key words: arch bridge, damage detection, operational modal analysis, vehicle-structure interaction

\section{Introduction}

Experimental tests constitute the most reliable method to obtain the dynamic properties (natural frequencies, mode shapes and damping ratios) of actual structures and to validate, from these results, numerical models used for their

* Corresponding author. Tel.: +34 954487293; fax: +34 954487295.

Email address: jose@us.es (J. Domínguez). 
analysis. They permit also to asses the state of damage of a structure by comparison with the dynamic properties obtained in previous analyses.

Dynamic identification methods from ambient vibration have been used in complicated structures like dams [1], offshore platforms [2], sports stadia [3], bridges [4], etcetera. A theoretical and experimental research work in relation to Barqueta bridge is described in this work. It is a steel arch bridge with cable-stayed deck that links the old town of Seville with the Scientific Park Cartuja 93. At certain hours, a traffic jam occurs on the bridge and cars cover one half of the bridge lanes (Fig. 1) for more than one hour.

The experimental program developed in this work includes the dynamic characterization of the structure for two situations under normal conditions and when it is covered by traffic. The modal properties of the bridge are identified from ambient vibration and the results obtained for both situations of the bridge are compared. By this analysis, the effect that vehicles have on the dynamic behaviour of the structure is studied. The idea presented in [3], where changes of the modal properties of a sport stadium were determined at times when different activities took place at the stadium, is explored in this paper for the bridge case. The authors of that paper concluded that the dynamic properties of the structure depend to some extent on the type of the activity celebrated in the stadium. The possibility of these changes taking place in other types of structures is studied in this work.

The obtained experimental results are compared with those from a threedimensional finite element analysis. Finally, a damage identification methodology is applied to verify the structural integrity of the bridge. Experimental results obtained with a time difference of one year and a temperature difference of $10^{\circ} \mathrm{C}$ are analyzed.

\section{Description of the structure}

The aesthetic functions and symbolic values of the structures are more and more important every day, in particular when these structures are built in urban zones [5,6]. Barqueta bridge was built in Seville for the 1992 International Exhibition $[7,8]$. It is an innovative structure, designed by JJ. Arenas and M. Pantaleón, with a flying central arch rising from the vertex of two lateral triangular frames. Fifteen years after its construction, Barqueta is an indispensable piece of the urban landscape of Seville. Barqueta is a bowstring steel bridge. The $168 \mathrm{~m}$ span structure rests on two sets of two vertical supports spaced $30 \mathrm{~m}$ in the transverse direction located at the banks of the Guadalquivir river (Figs. 1-3). The cross-sections of the arch and inclined legs include deep grooves that produce enough local inertia to avoid the need of any internal 
longitudinal stiffener.

The deck cross-section is shown in Fig. 2. It is $16 \mathrm{~m}$ wide and $2.4 \mathrm{~m}$ deep. The total wide of the bridge is $21 \mathrm{~m}$ with two cantilever pedestrian decks. The deck cross-section includes two vertical webs separated by a distance of $1 \mathrm{~m}$ (see Fig. 2). The hangers are anchored between then. The hangers have variable inclination. The deck is supported on the extremes by transversal beams, with variable depth, which rest on the vertical supports.

\section{$3 \quad$ Finite Element Model}

A three dimensional finite element model (FEM) has been developed for the numerical analysis of the structure using as-built drawings of the bridge and some double-check in-situ measurements. Modal analysis was carried out using ANSYS [9].

The arch, supports, and the internal stiffener were represented as two-node beam elements (BEAM44) with 6 degrees of freedom per node. This element permits the end nodes to be offset from the centroidal axis of the beam. The hangers were modeled as truss elements (LINK10) with 3 degrees of freedom per node. The deck slab was modeled using eight-node shell elements with 6 degrees of freedom per node (SHELL93). The two extreme beams and the vertical supports were connected by spring elements (COMBINE14).

A detailed model of all the bridge elements was intended. As a consequence, the number of degrees of freedom is high. The full model consists of 10328 beam elements, 17 truss elements, 15672 shell elements and 8 spring elements, resulting into 26025 elements and 47024 nodes. Fig. 3 shows a full 3-D view of the finite element model of the bridge and details of the deck cross-section.

\section{Full-scale testing}

Dynamic properties can be obtained by measurement of vibrations produced by ambient loads. This technique is simpler for civil engineering structures than classical modal analysis because it is not necessary to excite the structures by shakers. In addition, the structure can be used during the testing process.

The experimental program, carried out during July 152005 and October 11 2006, includes dynamic characterization of the structure in normal conditions and when a half of the bridge is covered by traffic. The response of the structure was measured at 16 selected points (Fig. 4) using Endevco (Model 86 and 
Model 4370) accelerometers. Preliminary results obtained from a FE dynamic analysis were used to determine the optimum location of the sensors.

Since nine Model 86 accelerometers were available for the testing and two of these sensors (at locations 1 and 2) were held stationary for reference during the test carried out in 2005 and one of them (at location 2) during the test developed in 2006, two set-ups were required to cover the 16 measurement points. It is worth to mention that in output-only modal analysis, where the input force remains unknown and may vary between the set-ups, the different measurements setups can only be linked if there are some sensors in common. The reference accelerometers were chosen in order to be able very carefully to measure all global modes of the bridge.

The hangers were not instrumented in the first test because, according to preliminary numerical analysis and preceding experimental studies $[10,11]$, significant interaction between the stay-cables and the rest of the structure was not expected. This interaction is significant when the lowest natural frequencies of the structure and the natural frequencies of the cables are close. In the present case, cables are short, estimating their first natural frequencies around $6 \mathrm{~Hz}$. There are at least, 10 global modes of the structure below this values. Therefore it is not expected that cables have an important participation in the global modes of the bridge. This assumption was validated by the second test, where the cables were instrumented (Figure 5a.). The power spectral density of the cable's response is shown in Figure 6 where it can be observed that the first bending mode of the cable is around $6 \mathrm{~Hz}$.

During the first test, data of the response of the structure were acquired when the structure was under fluid traffic conditions, in locations 1 to 9 , and when cars cover one half of the lanes of the bridge, in points 1,2 and 10 to 16 . In order to obtain the mode shapes of the structure, the response at all points have been used. Traffic-structure interaction is not expected to cause changes in structural mode shapes. Natural frequencies and damping ratios, were determined using each one of the set-ups independently. In the second test, the response of the structure was acquire in all locations for both situations: when the structure is under fluid traffic conditions and when cars cover one half of the lanes of the bridge.

Ambient vibration response was acquired during 1000 seconds per channel and per set-up. The data were sampled to $64 \mathrm{~Hz}$. Data were decimated (order 3) to carry out data analysis in the frequency range of interest (0 to $10 \mathrm{~Hz}$ ). Data records were Hannning-windowed with $66.67 \%$ overlapping for spectral averaging.

Acquired data are available for interested reader by sending an e-mail message to the authors. 


\section{Data Analysis}

Different procedures to obtain modal parameters from ambient vibration data have been used in this work. In output-only modal analysis, also called operational modal analysis, the applied forces are unknown and, therefore, neither the frequency response function nor the impulse response function can be obtained to determine modal parameters as in classical modal analysis [12]. The signal at one of the fixed transducers is used as a reference to determine the frequency response function and the impulse response function.

Four complementary identification methods have been considered in the present work: three of them based on frequency domain analysis and one on time domain analysis. The study has been developed using MATLAB [13] and ARTEMIS [14] software.

The first identification method employ is Peak-Picking (PP), which has been used with success in many other applications $[5,11,15,16]$. This method is based on the fact that when the frequency response function reaches a peak at a certain frequency, it can be associated to the force or to a resonance frequency of the structure [17]. Natural frequencies are identified from peaks of spectral densities function:

$$
\omega_{d i}=\sqrt{1-\xi_{i}^{2}} \cdot \omega_{n i}
$$

This procedure produce a good estimations of natural frequencies for weakly damped structures. To distinguish between peaks associated to the excitation and those associated to resonance frequencies of the structure, mode shapes can be used [17]. The response values at all points of a weakly damped structure for one of its resonance frequencies, are in phase or out of phase by $180^{\circ}$, depending on the mode shape. Peaks of spectra density function associated to the excitation normally present a phase difference of the cross-spectra function between two measurements points different from $0^{\circ}$ or $180^{\circ}$. In addition, the coherence function between two signals has a value close to one for the resonance frequencies of the structure, due to the high relation response-noise at those frequencies. This fact helps to decide which of the frequencies really are natural frequencies of the structure. The PP method is based on the assumption that the dynamic response of the structure at resonance peaks is determined for each mode. This is valid when modes are well separated. Therefore, it is difficult to identify modes very close to each other using this method. The auto-spectra, cross-spectra and coherence functions obtained from the first test, are shown in Fig. 7. The natural frequencies were identified from resonance peaks in auto-spectra and cross-spectra functions. Coherence function peaks are the same that the peaks of the previous functions, and the phase value of the cross-spectra function for those peaks are $0^{\circ}$ or $180^{\circ}$, providing 
additional evidence that these peaks correspond to natural frequencies of the structure.

The second identification technique used in the present study is the so called Averaged Normalized Power Spectral Densities (ANPSDs) which is a practical implementation, developed by Felber [18], of the PP method. In this case, autospectra functions are normalized and averaged to obtain an average spectra density function that, normally, shows all resonance frequencies of the system.

$$
A N P S D(\omega)=\frac{1}{l} \sum_{i=1}^{l} \frac{P S D(\omega)}{\sum_{j=1}^{n} P S D\left(\omega_{j}\right)}
$$

where $l$ is the number of measurement locations. The natural frequencies of the structure are obtained from the simple observation of the peak in the ANPSDs diagram. This method was used successfully in the dynamic characterization of an arch bridge in reference [19]. The ANPSDs diagrams for both situations of the bridge obtained from the first test are shown in Fig. 8.

The third identification technique used, also in the frequency domain, is called Enhanced Frequency Domain Decomposition (EFDD) [20] which, from a simple form, introduces significant improvements to Peak Picking Technique. This method is based on a modal decomposition realization of the spectral density matrix, being one of the advantages of the method the possibility to identify very close modes.

The Power Spectral Density matrix (PSD) of the $m$ measured responses can be expressed, for a lightly damped structure, as:

$$
G_{y y}(j \omega)=\sum_{k \in S u b(\omega)} \frac{d_{k} \phi_{k} \phi_{k}^{T}}{j \omega-\lambda_{k}}+\frac{\bar{d}_{k} \bar{\phi}_{k} \bar{\phi}_{k}^{T}}{j \omega-\bar{\lambda}_{k}}
$$

where $d_{k}$ is a scalar constant, $\phi_{k}$ is the mode shape vector, $\lambda_{k}$ is the pole of the output PSD, and $S u b(\omega)$ is the limited number of modes that will contribute to the response at frequency $\omega$.

The first step of the EFDD is to estimate the output PSD matrix at discrete frequencies, and to carry out the Singular Value Decomposition (SVD) of the matrix

$$
\hat{G}_{y y}\left(j \omega_{i}\right)=U_{i} S_{i} U_{i}^{H}
$$

where the matrix $U_{i}$ contains the singular vectors $u_{i j}$ and $S_{i}$ is a diagonal matrix with the scalar singular values $s_{i j}$. Close to a peak, where the $k$ mode is dominant, there will be only one mode in $S u b(\omega)$ and, therefore, the first singular vector $u_{k 1}$ is an estimate of the mode shape; i.e., $\hat{\phi}_{k}=u_{k 1}$, and the corresponding singular value is the auto power spectral density function of the singular degree of freedom system. This power spectral density function is identified around the peak comparing the estimated mode shape $\hat{\phi}_{k}$ with the 
singular vectors from the frequency lines around the peak. If the MAC value obtained from the singular vector and $\hat{\phi}_{k}$ is higher than a reference value close to one, the singular value belongs to the auto power spectral density function. Once the auto power spectral density function has been obtained around the peak, the natural frequency and the damping ratio are estimated by Inverse Fast Fourier Transform. The singular values decomposition of the spectral density matrix is shown in Fig. 9. Peaks representing vibration modes have been selected.

It can be observed that two modes very close to $2 \mathrm{~Hz}$ exist for the bridge under study, one of them not been determined by the previous methods. This type of modes can be easily identified with EFDD, by observation not only of the highest singular value but also of the next one.

The last technique is a more elaborated mathematical procedure that works directly with time domain acquired data. It is called Stochastic Subspace Identification (SSI). The interested reader can find details of the mathematical approach in references [21,22]. SSI is a powerful tool (perhaps the most advanced identification method that exists up to day) that has been used for dynamic characterization of many structures $[21,23,24]$. A brief review of the main ideas of this method is presented in the following.

The dynamic behaviour of a structure is described by:

$$
\mathbf{M} \ddot{\mathbf{U}}(t)+\mathbf{C} \dot{\mathbf{U}}(t)+\mathbf{K U}(t)=\mathbf{F}(t)
$$

where $\mathbf{M}, \mathbf{C}$, and $\mathbf{K}$ are the mass, damping, and stiffness matrices of the structure, respectively. $\mathbf{U}(t)$ and $\mathbf{F}(t)$ are the displacement and input force vectors respectively. This equation can be written as a state space equation:

$$
\dot{x}(t)=\mathbf{A}_{c} x(t)+\mathbf{B}_{c} u(t)
$$

where the state vector $x(t)=[\mathbf{U}(t), \dot{\mathbf{U}}(t)]^{T}$ and the state matrix $\mathbf{A}_{c}$, and the system control influence coefficient matrix $\mathbf{B}_{c}$, are defined by

$$
\mathbf{A}_{c}=\left(\begin{array}{cc}
0 & I \\
-\mathbf{M}^{-1} \mathbf{K} & -\mathbf{M}^{-1} \mathbf{C}
\end{array}\right) \quad \mathbf{B}_{c}=\left(\begin{array}{c}
0 \\
-\mathbf{M}^{-1}
\end{array}\right) \quad \text { where } \quad \mathbf{F}(t)=\mathbf{B}_{2} u(t)
$$

The output vector $y(t)$ can be expressed as

$$
y(t)=\mathbf{C}_{c} x(t)+\mathbf{D}_{c} u(t)
$$

where $\mathbf{C}_{c}$ is the output influence coefficient matrix and $\mathbf{D}_{c}$ is the output control influence coefficient matrix. These equations constitute a continuous-time state space model of a dynamic system. 
Since experimental data are discrete, a discrete-time state space model can be obtained by sampling the continuous-time state space model:

$$
\begin{aligned}
x_{k+1} & =\mathbf{A} x_{k}+\mathbf{B} u_{k} \\
y_{k} & =\mathbf{C} x_{k}+\mathbf{D} u_{k}
\end{aligned}
$$

where $x_{k}=x(k \Delta t)$ is the discrete-time state vector containing the sampled displacements and velocities; $u_{k}, y_{k}$ are the sampled input and output, respectively; $\mathbf{A}=\exp \left(\mathbf{A}_{c} \Delta t\right)$ is the discrete state matrix;and $\mathbf{B}=\left[\begin{array}{ll}\mathbf{A} & -I\end{array}\right] \mathbf{A}_{c}^{-1} \mathbf{B}_{c}$ is the discrete input matrix.

Including the stochastic components; i.e., the noise due to disturbances and modeling inaccuracies $\left(w_{k}\right)$ and the noise due to sensor inaccuracy $\left(v_{k}\right)$, the discrete state space model can be written as:

$$
\begin{array}{r}
x_{k+1}=\mathbf{A} x_{k}+\mathbf{B} u_{k}+w_{k} \\
y_{k}=\mathbf{C} x_{k}+\mathbf{D} u_{k}+v_{k}
\end{array}
$$

The process noise $w_{k}$ and measurement noise $v_{k}$ are assumed to be zero-mean, white noise, statistically independent, and with covariance matrices

$$
E\left[\left(\begin{array}{c}
w_{p} \\
v_{p}
\end{array}\right)\left(\begin{array}{ll}
w_{p}^{T} & v_{p}^{T}
\end{array}\right)\right]=\left(\begin{array}{cc}
\mathbf{Q} & \mathbf{S} \\
\mathbf{S}^{T} & \mathbf{R}
\end{array}\right) \delta_{p q}
$$

where $E$ is the expected value operator and $\delta_{p q}$ is the Kronecker delta. $\mathbf{Q}, \mathbf{R}$ and $\mathbf{S}$ are process and measurement noise covariance matrices.

In ambient vibration testing, only the responses of the structure are measured, obtaining:

$$
\begin{aligned}
x_{k+1} & =\mathbf{A} x_{k}+w_{k} \\
y_{k} & =\mathbf{C} x_{k}+v_{k}
\end{aligned}
$$

where the input $u_{k}$ is modeled by the noise terms.

This equation constitutes the basis for time domain modal identification from ambient vibration testing. There are several techniques to carry out modal identification based on this equation.

Fig. 10 shows a stabilization diagram obtained by applying SSI. System order and stable poles can be found in these diagrams which provide modes of the structure. 


\section{Dynamic behaviour of the bridge}

The dynamic behaviour of Barqueta Bridge is governed by vertical bending and torsional modes, in the frequency range of $0-6 \mathrm{~Hz}$. Ten modes have been identified in this frequency range. Table 1 shows the obtained natural frequencies for the bridge under fluid traffic conditions whereas Table 2 corresponds to the situation when the bridge is jammed. Damping ratios obtained for both bridge conditions are shown in Tables 3 and 4 .

It is observed in both tests that the natural frequencies of the structure change very little due to the traffic conditions on the bridge. The first test was carried out on July 2005, while that the second one took place on October 2006, with an ambient temperature difference of $10^{\circ} \mathrm{C}$. Very little changes appear in the natural frequencies obtained from the two experimental tests as can be seen from the values shown in Tables 1 and 2. Damping ratios may increase up to 200 per cent when the bridge is jammed with vehicles, as compared to the empty situation. Increments in damping ratios of the same order were observed in both series of tests. A very similar conclusion was reached in [3], where it was concluded that the damping ratios in a sport stadium increases to a significant extent when it is crowded.

Mode shapes of the structure identified from experimental modal analysis and from numerical analysis are shown in Figs. 11 and 12.A complete agreement between both sets of mode shapes can be observed.

In order to quantify this agreement, experimental results have been compared with the finite element results by using the Modal Assurance Criterion (MAC) [25]. MAC values vary from 0 to 1 ; a value of one implies perfect correlation of the two modes vectors (one vector is proportional to the other), while a value close to zero indicates no correlated modes (orthogonal modes). The MAC value is defined as:

$$
\operatorname{MAC}\left(\phi_{A, k}, \phi_{B, j}\right)=\frac{\left(\phi_{A, k}^{T} \phi_{B, j}\right)^{2}}{\left(\phi_{A, k}^{T} \phi_{A, k}\right)\left(\phi_{B, j}^{T} \phi_{B, j}\right)}
$$

where $\phi_{C, k}$ is the k-mode of data set $C$, and ${ }^{T}$ means transpose matrix.

The obtained MAC matrix between the results obtained from the test carried out in 2005 and those obtained from the test carried out in 2006, are shown in Fig. 13. The mode vector correlation using MAC seems quite good, finding the highest difference in the fifth mode shape. The MAC matrix between the numerical and experimental results have also obtained. Fig. 14 shows that there is a quite good agreement between experimental and numerical results. Therefore, the numerical model can be used to represent the dynamic behaviour of the bridge. 
One of the objectives of this work is to obtain some reference data to detect future damage of Barqueta Bridge, by comparing dynamic parameters obtained along its life. In this work, the modal parameters obtained in 2005 have been compared to those obtained in 2006. The damage state has been evaluated using Damage Index Method [26]. In this method, the damage state is controlled by the index $\beta$, based on the decrease in modal strain energy between two structural degrees of freedoms, as defined by the curvature of the measured mode shapes. For a point $j$ of the structure, the strain energy change between the reference state and the current state, for the $i$ mode shape, is related with curvature changes at the point $j$. The damage index at point $j$, for mode shape $i$, is defined as:

$$
\beta_{i j}=\frac{\int_{a}^{b}\left[\psi^{\bullet^{\prime \prime}}(x)\right]^{2} d x+\int_{0}^{L}\left[\psi^{\bullet^{\prime \prime}}(x)\right]^{2} d x}{\int_{a}^{b}\left[\psi^{\prime \prime}(x)\right]^{2} d x+\int_{0}^{L}\left[\psi^{\prime \prime}(x)\right]^{2} d x} \cdot \frac{\int_{0}^{L}\left[\psi^{\prime \prime}(x)\right]^{2} d x}{\int_{0}^{L}\left[\psi^{\bullet^{\prime \prime}}(x)\right]^{2} d x}
$$

where $\psi^{\prime \prime}(x)$ and $\psi^{\bullet \prime}(x)$ are the second derivates of the $i$ mode shape, in the reference state and the current state, respectively; $L$ is the length of the beam element (the structure is discretized by beam elements); and, $a$ and $b$, are the ends of the element in which the damage is evaluated. When two or more mode shapes are used to identify the state of damage, the obtained indexes for each mode shape are added. An interpolation using spline polynomials is carried out to determine the modal shapes at points in which there are not transducers.

It would be useful to introduce some artificial damage in the bridge in order to validate this methodology. However, it has not been possible to do so. As an alternative, a simpler structure has been built to validate this technique in the laboratory. The structure is a steel frame where a beam has been damaged. Using the proposed technique, the damage was located with an error lower than $3 \%$.

The damage index obtained from experimental modal analyses for Barqueta bridge is shown in Fig. 15. It can be observed that the $\beta$ value is practically one at all points. This means a perfect correlation of the two analyses. It was expected, from previous observation by MAC, that both groups of results were quite well correlated. Results indicate that the bridge has not suffered any damage during the last year.

\section{Conclusions}

An experimental and numerical procedure, developed to obtain the dynamic behaviour of an arch bridge with cable-stayed deck, has been presented. The modal parameters of the bridge are evaluated from ambient vibration using 
different identification techniques. EFDD and SSI techniques have shown their efficiency to identify different modes close to each other.

The dynamic behaviour of Barqueta Bridge is governed by vertical bending modes and torsional modes in the frequency range of 0-6 Hz. Ten vibration modes have been identified in this frequency range. Consistency in the obtained results from the different records and the coherence information, indicate that the structure had a linear behaviour during tests.

Using MAC, the obtained experimental modes have been compared with those evaluated from a finite element analysis. A quite good agreement between numerical and experimental results is observed.

Vehicle-structure interaction has been studied for situations when half of the bridge is totally covered by vehicles. These vehicles, in addition to add mass to the structure, produce an increase in the estimated damping ratios. It is sensible to conclude that vehicles act as energy dissipation mechanisms.

The results of this investigation can be applied to verify the integrity of the structure along its life. The results obtained from different experimental modal analyses done using the data recorded in two series of test carried out with a time difference of one year, have been correlated using the damage index method in order to evaluated the damage state of the structure.

\section{Acknowledgements}

This research is financed by the Ministerio de Educación y Ciencia of Spain under the research project BIA2004-03955-C02-01 and by the Ministerio de Fomento of Spain under the research project "Evaluación de efectos dinámicos del ferrocarril". The financial support is gratefully acknowledged.

\section{References}

[1] Kemp BG. Ventura CE. Anderson DL. Felber AJ. Ambient Vibration Measurement of Ruskin Dam for Seismic Assessment. Proceedings of 7th Canadian Conference on Earthquake Engineering. Canada, 1995: 641-648.

[2] Jensen JL. System identification of offshore platforms. Ph.D. Thesis, Aalborg University, Denmark; 1990.

[3] Reynolds P. Pavic A. Ibrahim Z. Changes of Modal properties of a stadia structure occupied by a crowd. Proceedings of International Modal Analysis XXII. USA, 2004. 
[4] Abdel-Ghaffer AM. Scalan RH. Ambient vibration of Golden Gate Bridge. I: Suspended structure. Journal of Engineering Mechanics 1985; 111: 463-482.

[5] Casas JR. Full-scale dynamic testing of the Alamillo cable-stayed bridge in Seville (Spain). Earthquake Engineering and Structural Dynamics 1995; 24: $35-51$.

[6] Troyano LF. Armisen JM. Suárez MAA. The inclined towers of the Ebro and Lerez Bridge. Structural Engineering International 1998; 8: 248-260.

[7] Arenas JJ. Pantaleón MJ. Puente de Barqueta, Sevilla, España. Structural Engineering International 1992; 2: 251-252.

[8] http://www.arenasing.com/ ingles/menu_1/proyectos/p_urbanos/barqueta/informacion.html.

[9] http://www.ansys.com.

[10] Deger Y. Cantieni R. deSmet CAM. Felber AJ. Finite element model optimization of the new Rhine bridge based on ambient vibration testing. Proceedings of EURODYN'96. Italy, 1996: 817-822.

[11] Gentile C. Martinez y Cabrera F. Dynamic performance of twin curved cablestayed bridges. Earthquake Engineering and Structural Dynamics 2003; 33: $15-34$.

[12] Ewins DJ. Modal Testing. Research Studies Press Ltd; 2000.

[13] http://www.matlab.com.

[14] http://www.svibs.com.

[15] Brownjohn JMW. Ambient vibration studies for system identification of tall buildings. Earthquake Engineering and Structural Dynamics 2003; 32: 71-95.

[16] Feng MQ. Kim JM. Xue H. Identification of a Dynamic System Using Ambient Vibration Measurements. Journal of Applied Mechanics 1998; 65: 1010-1021.

[17] Bendat JS. Piersol AG. Engineering Applications of Correlation and Spectral Analysis. Wiley \& Sons; 1980.

[18] Felber AJ. Development of a hybrid bridge evaluation system. Ph.D. Thesis, University of British Columbia, Canada; 1993.

[19] Zong ZH. Jaishi B. Ge JP. Ren WX. Dynamic analysis of a half-through concrete filled steel tubular arch bridge. Engineering Structures 2005; 27: 3-15.

[20] Brincker R. Zhang L. Andersen P. Modal Identification of Output-Only Systems using Frequency Domain Decomposition. Smart Materials and Structures 2001; 10: $441-445$.

[21] Peeters B. System Identification and Damage Detection in Civil Engineering. Ph.D. Thesis, Katholieke Universiteit Leuven, Belgium; 2000. http://www. kuleuven.be/bwm/papers/peet00a.pdf. 
[22] Van Overschee P. De Moor B. Subspace Identification for Linear Systems: Theory, Implementation, Applications. Kluwer Academic Publ.; 1996.

[23] Andersen P. Identification of civil engineering structures using vector ARMA models. Ph.D. Thesis, Aalborg University, Denmark; 1997. http://www. aub.auc.dk/phd/department06/text/p andersen01.pdf.

[24] De Roeck G. Peeters B. Ren W. Benchmark study on system identification trough ambient vibration measurements. Proceedings of International Modal Analysis XVIII. USA, 2000: 1106-1112.

[25] Allemang RJ. Brown DL. Correlation coeficient for modal vector analysis. Proceedings of International Modal Analysis I. USA, 1983: 110-116.

[26] Stubbs N. Kim JT. Farrar CJ. Field Verification of a Nondestructive Damage Localization and Severity Estimation Algorithm. Proceedings of International Modal Analysis XIII. USA, 1995. 


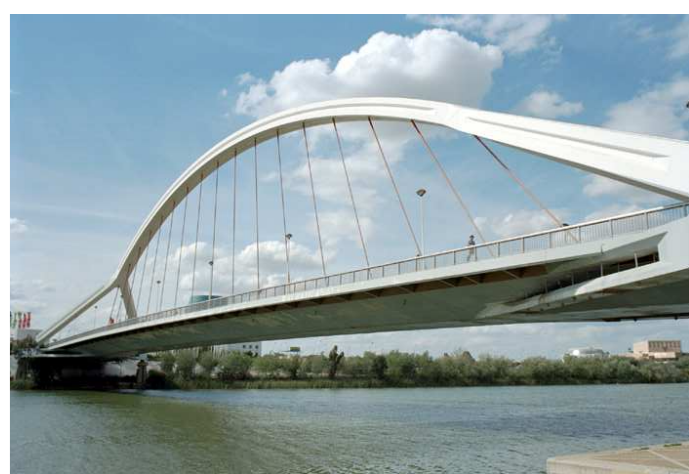

(a)

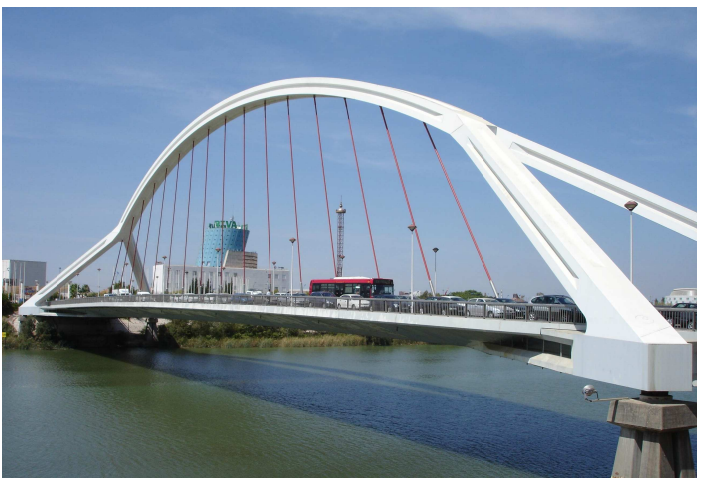

(b)

Fig. 1. Barqueta Bridge (a) and traffic jam on Barqueta Bridge (b). 


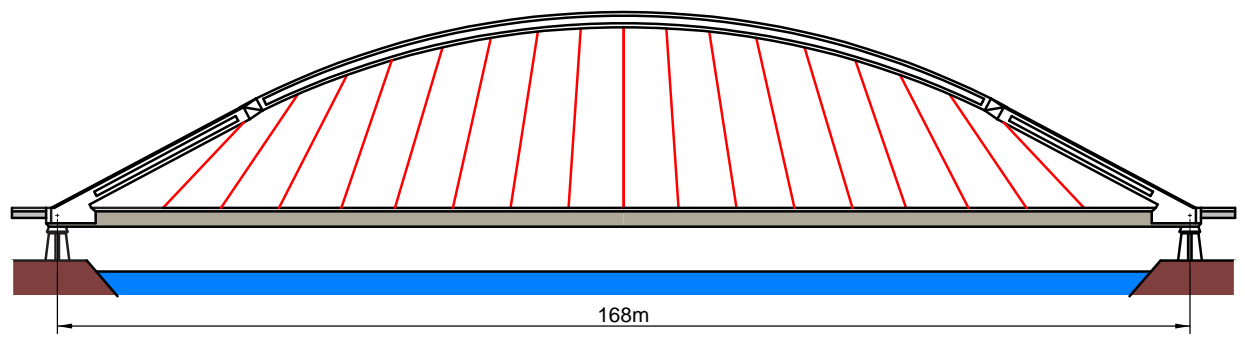

(a) Elevation

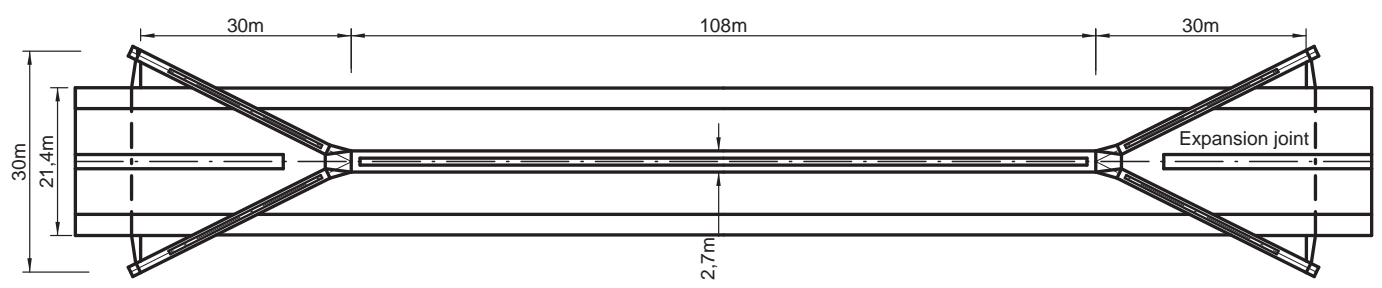

(b) Plan

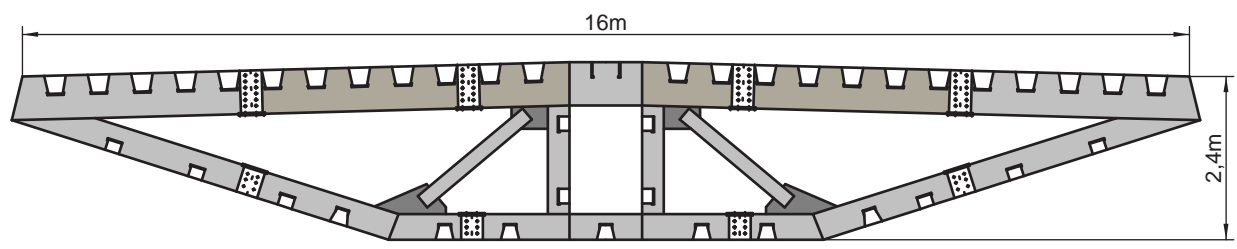

(c) Deck cross-section

Fig. 2. Elevation, plan and deck cross-section of Barqueta Bridge. 


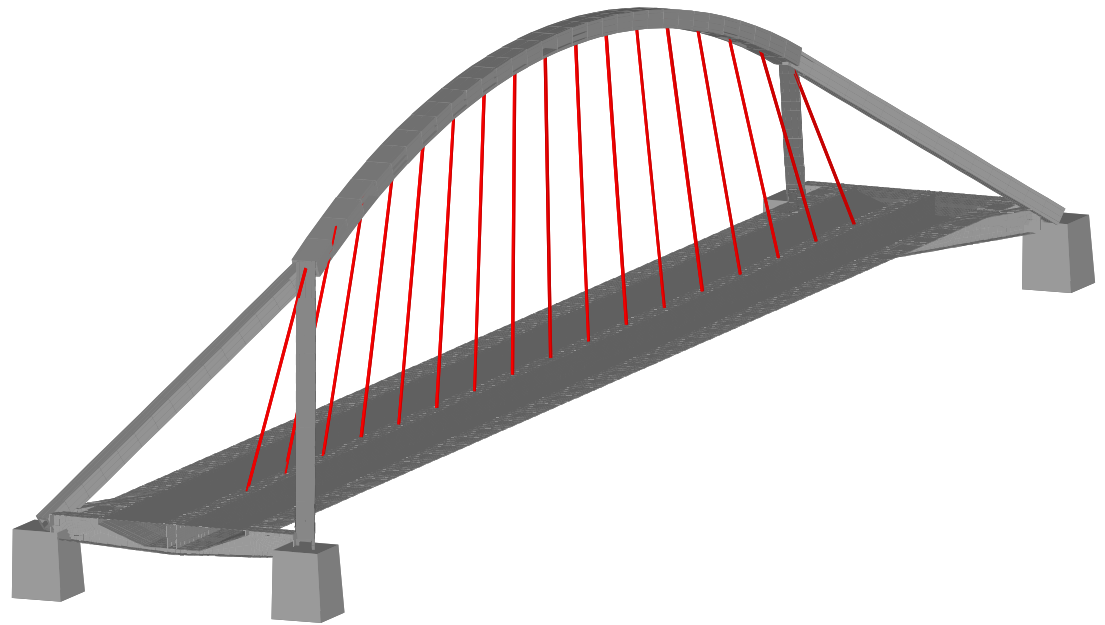

(a)

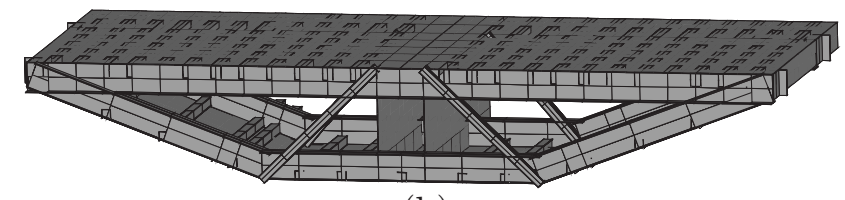

(b)

Fig. 3. The 3-D FE model of Barqueta Bridge (a) and detail of the deck cross-section model (b). 


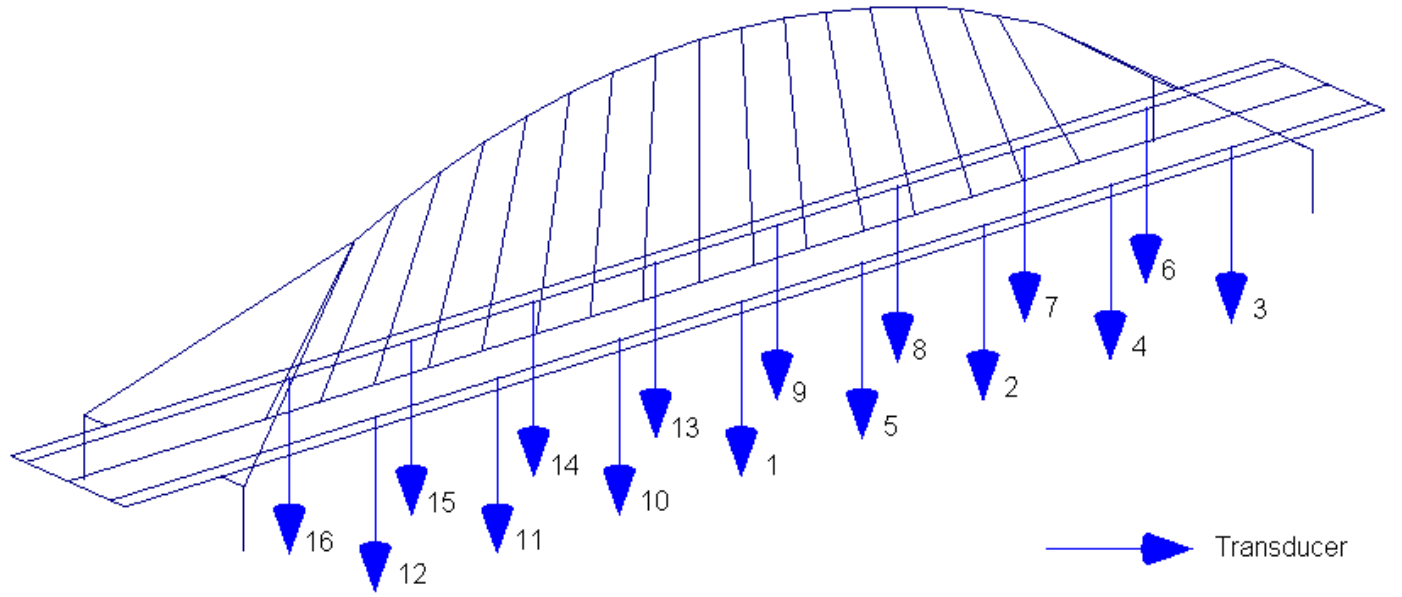

Fig. 4. Measurement locations. 


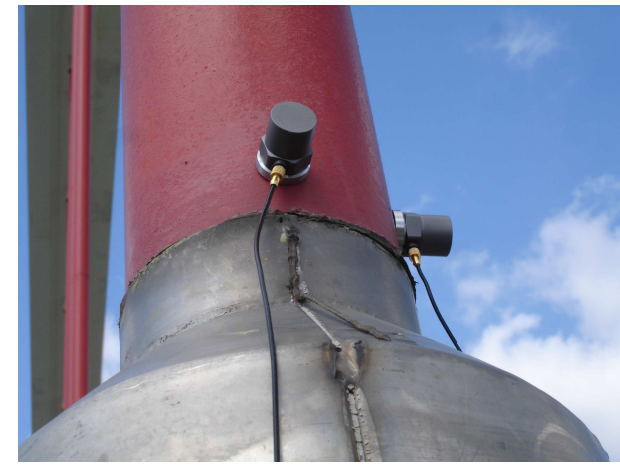

(a)

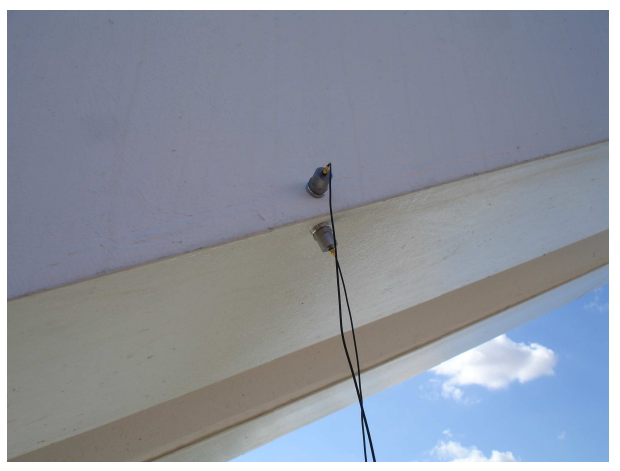

(b)

Fig. 5. Accelerometers at cables and arch member 


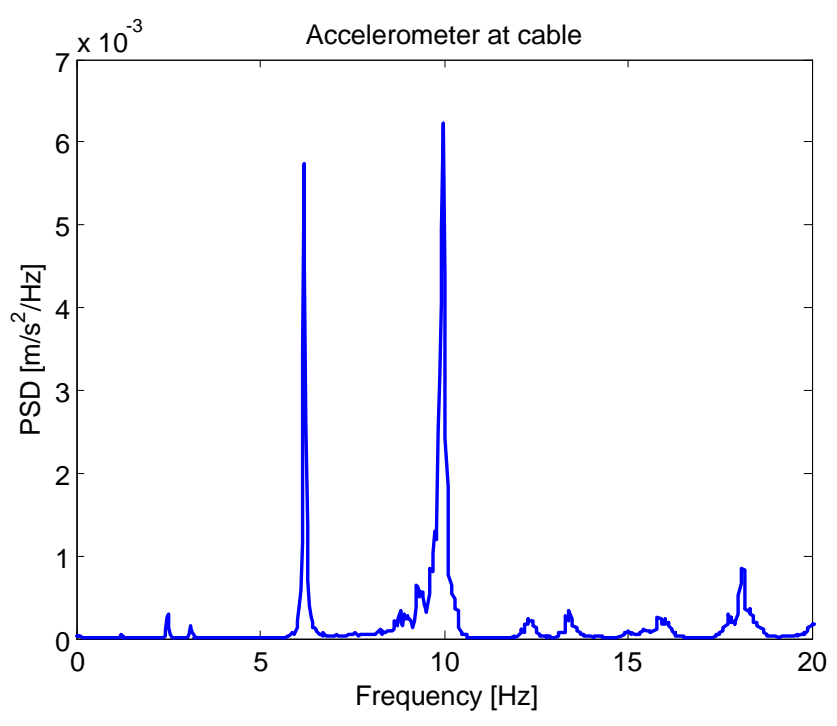

Fig. 6. Power spectral density of the cable's response 


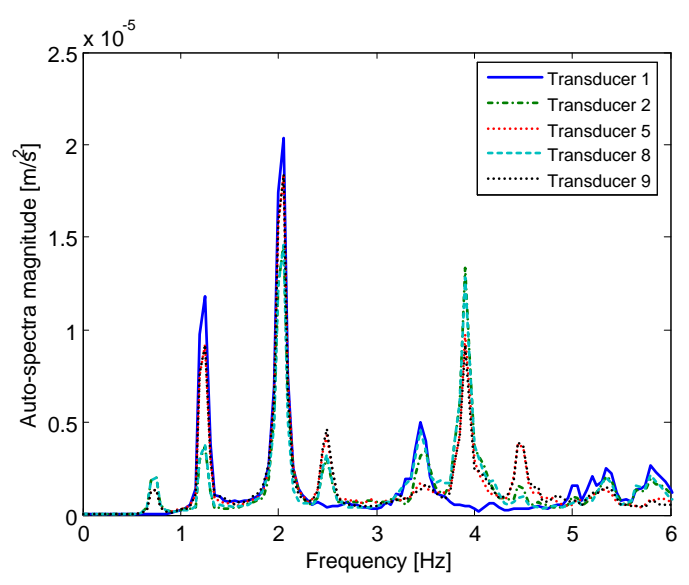

(a) Auto-spectra function

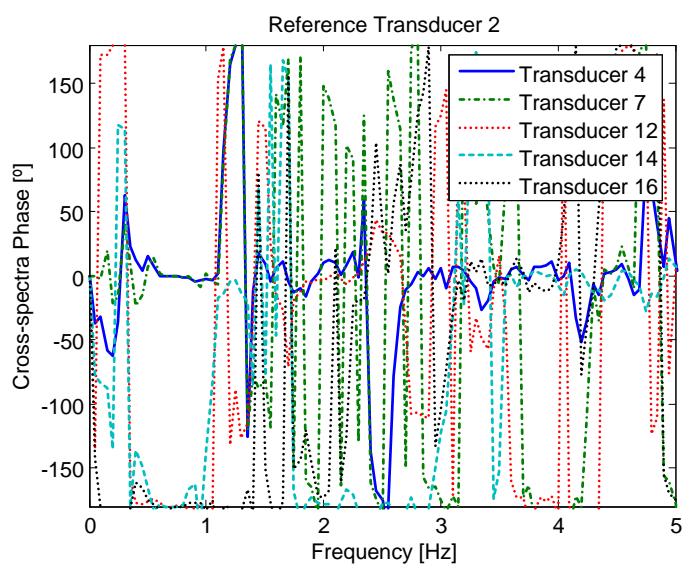

(c) Cross-spectra function (phase)

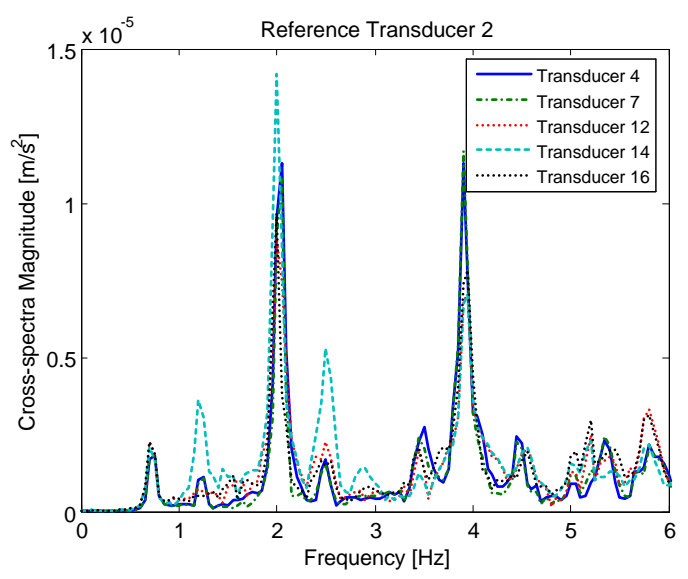

(b) Cross-spectra function (magnitude)

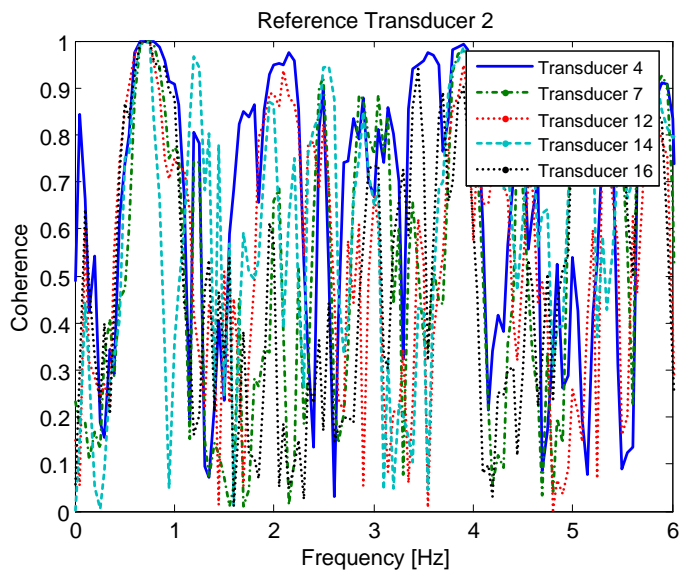

(d) Coherence function

Fig. 7. Auto-spectra function, cross-spectra function (magnitude and phase) and coherence function. 


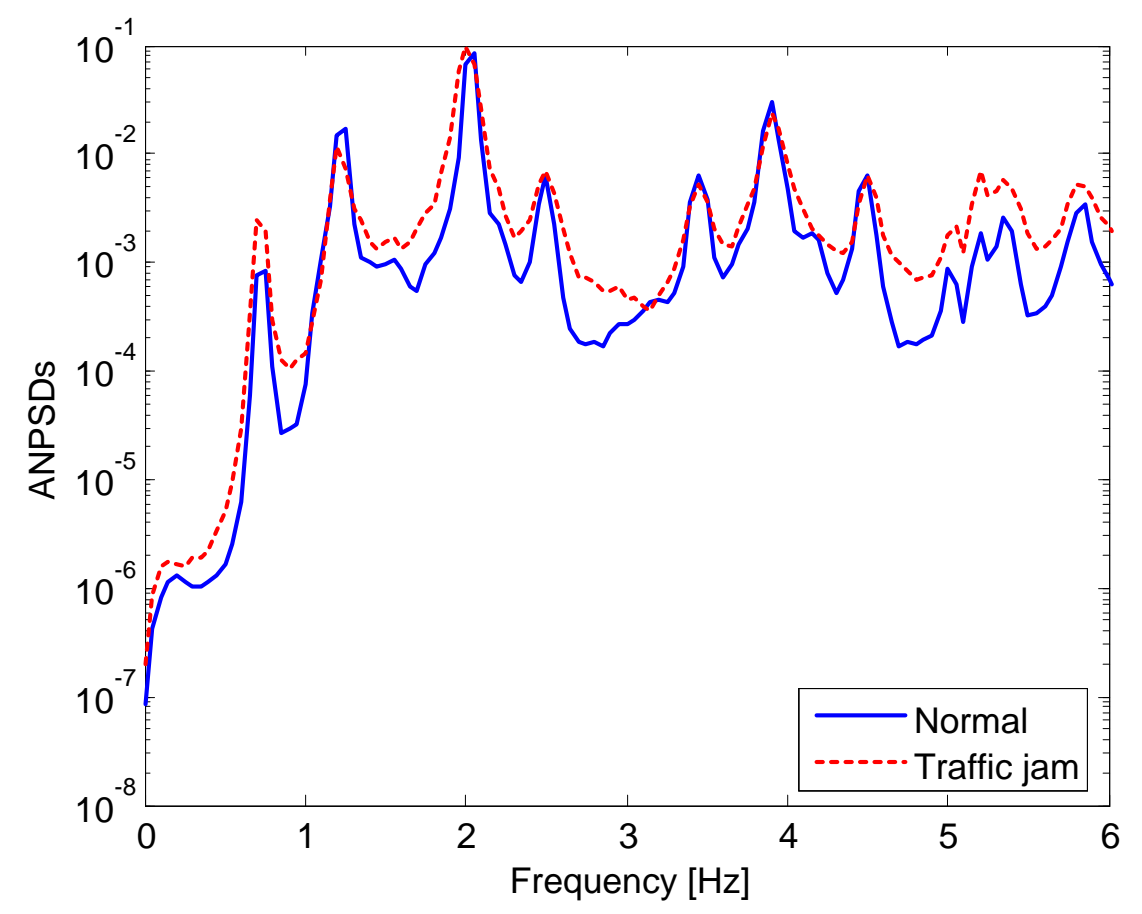

Fig. 8. Average Normalized Power Spectral Densities. 


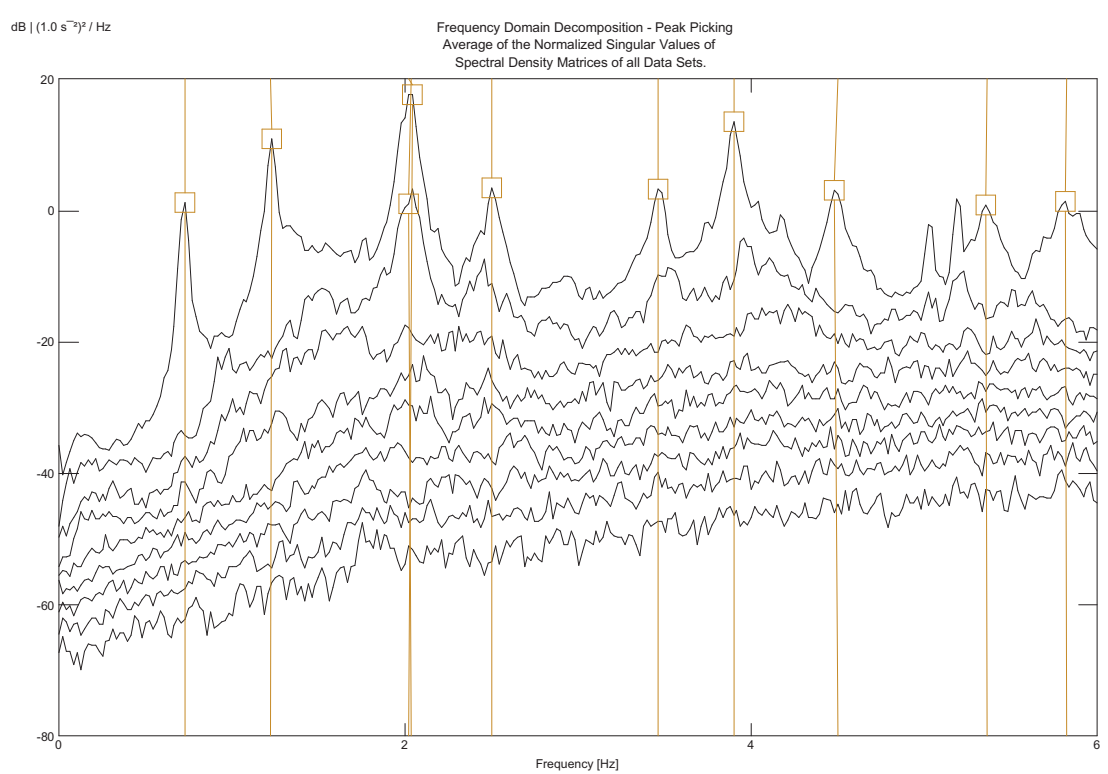

Fig. 9. Singular Value Decomposition of the Spectral Densities Matrices. 


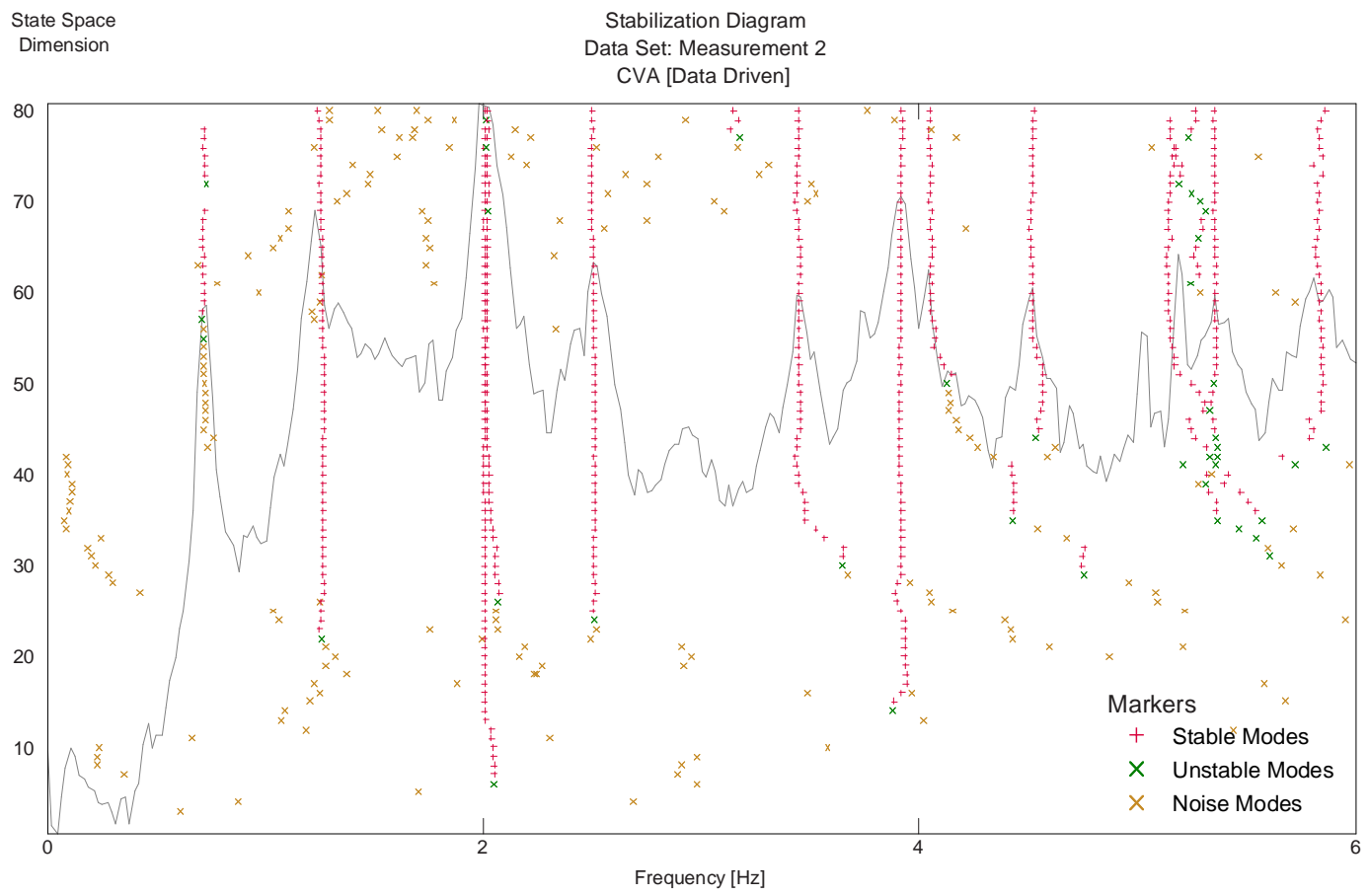

Fig. 10. Stabilization Diagram. 


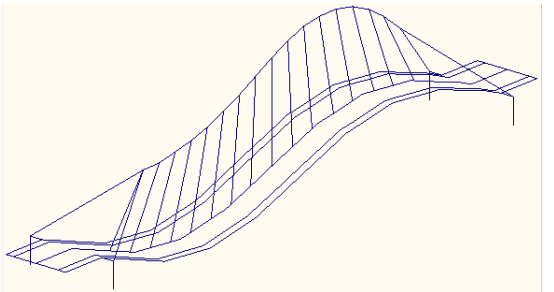

(a) Mode 1

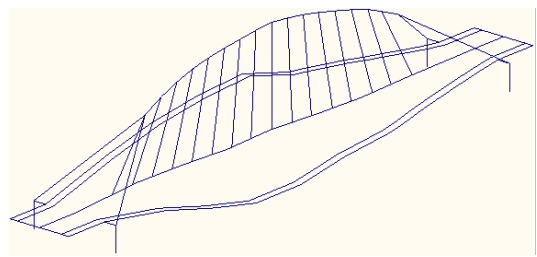

(c) Mode 3

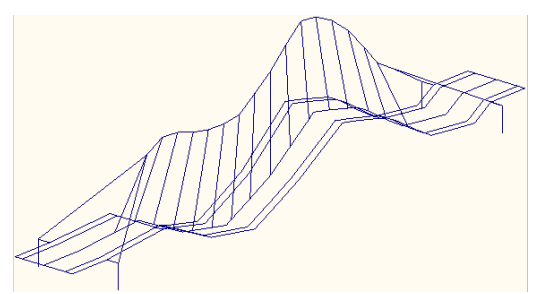

(e) Mode 5

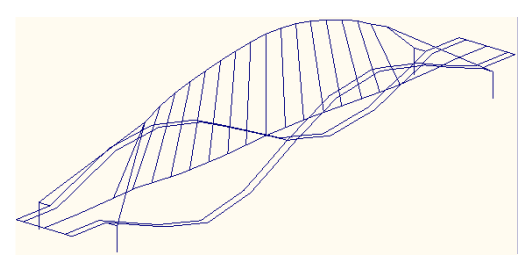

(g) Mode 7

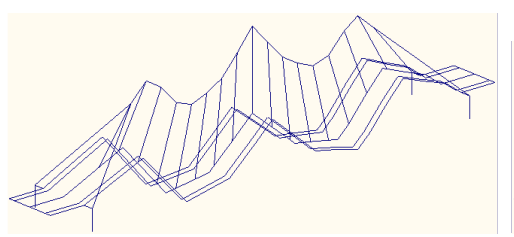

(i) Mode 9

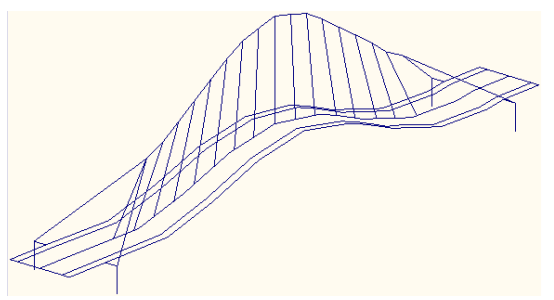

(b) Mode 2

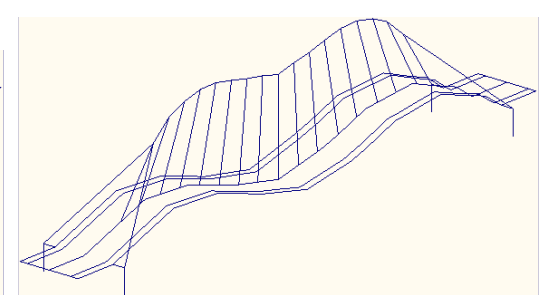

(d) Mode 4

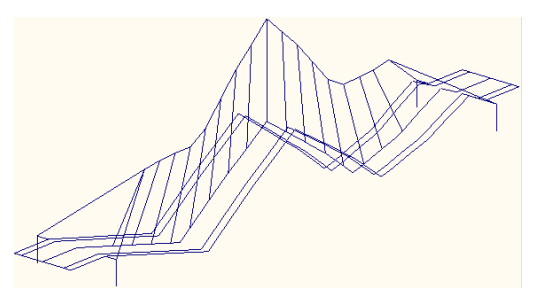

(f) Mode 6

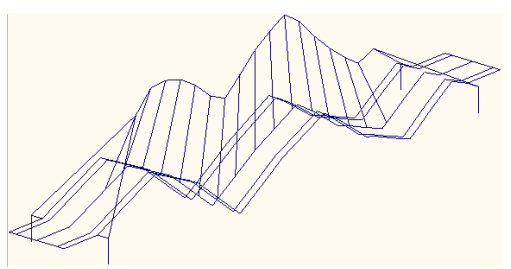

(h) Mode 8

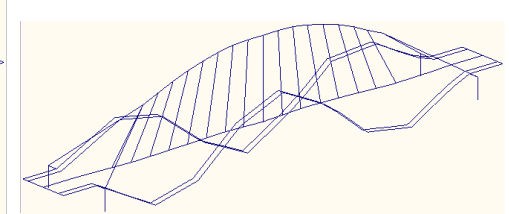

(j) Mode 10

Fig. 11. Mode shapes from experimental modal analysis. 


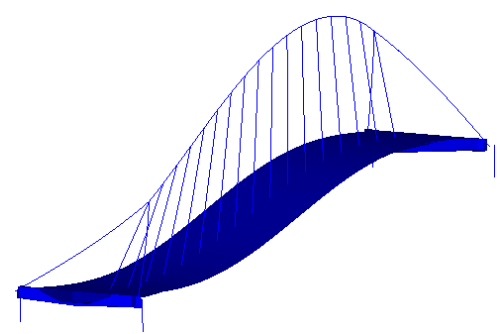

(a) Mode 1

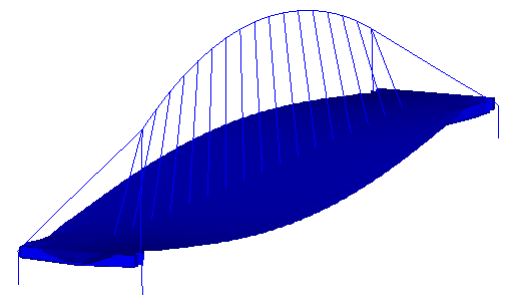

(c) Mode 3

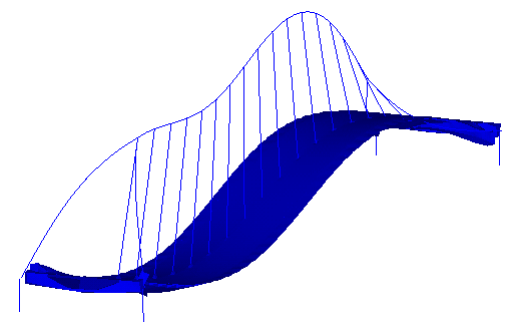

(e) Mode 5

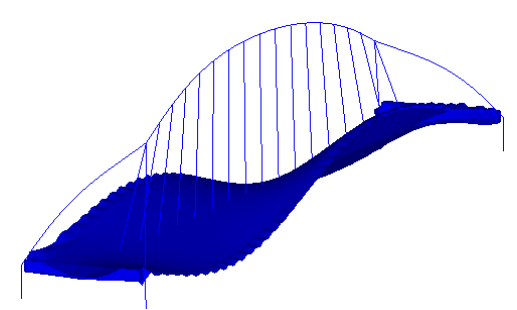

(g) Mode 7

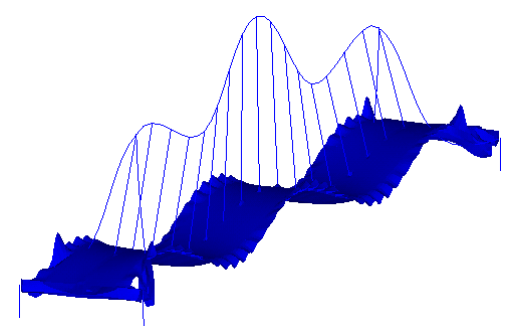

(i) Mode 9

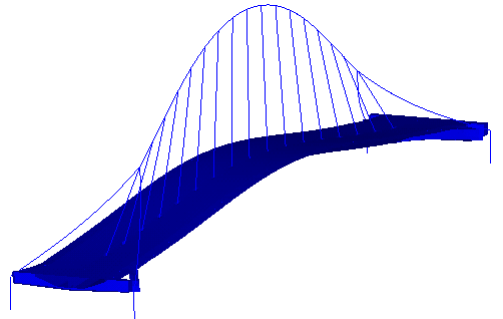

(b) Mode 2

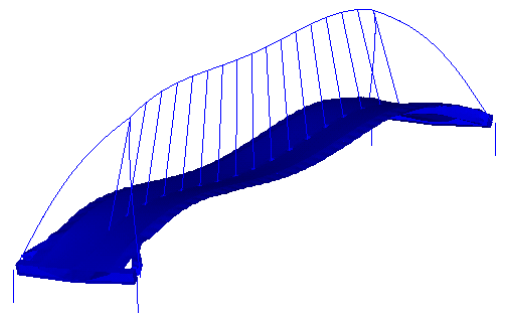

(d) Mode 4

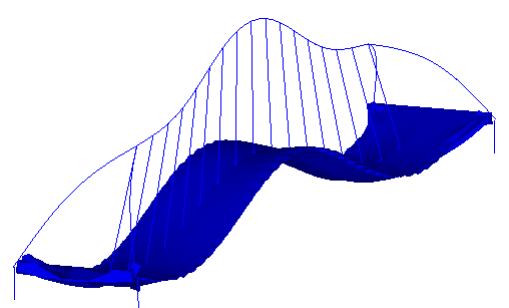

(f) Mode 6

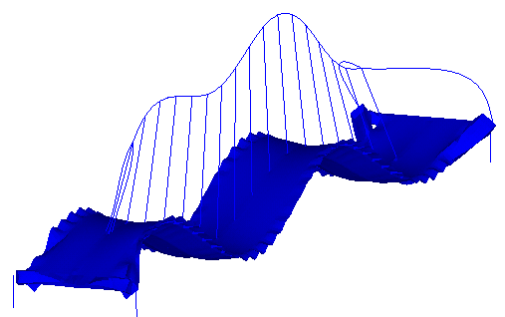

(h) Mode 8

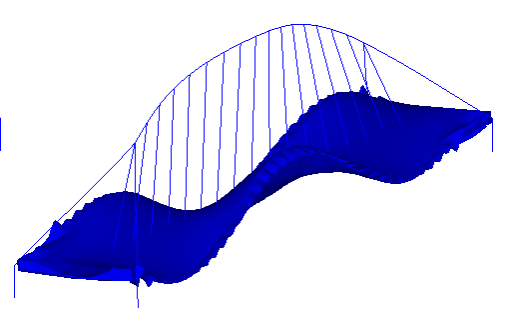

(j) Mode 10

Fig. 12. Mode shapes from numerical modal analysis. 


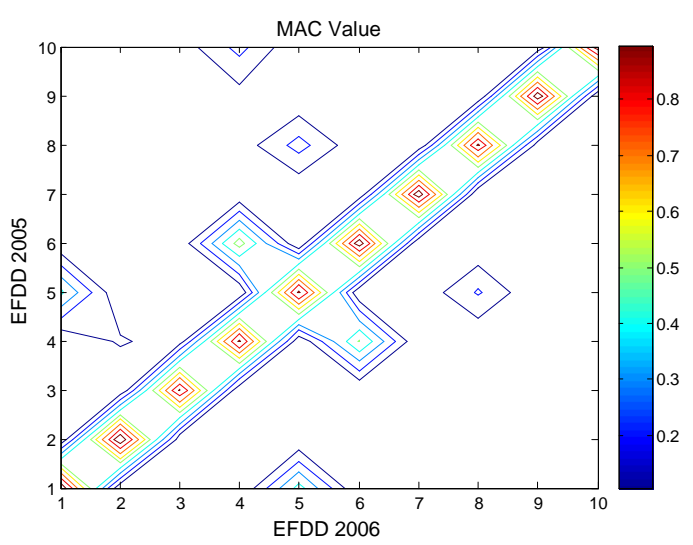

(a) MAC Matrix between EFDD results

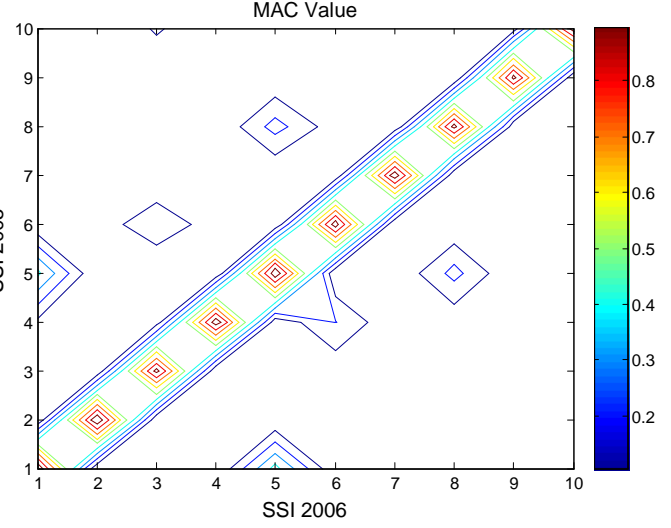

(b) MAC Matrix between SSI results

Fig. 13. MAC Matrix between results obtained in 2005 and those obtained in 2006. 

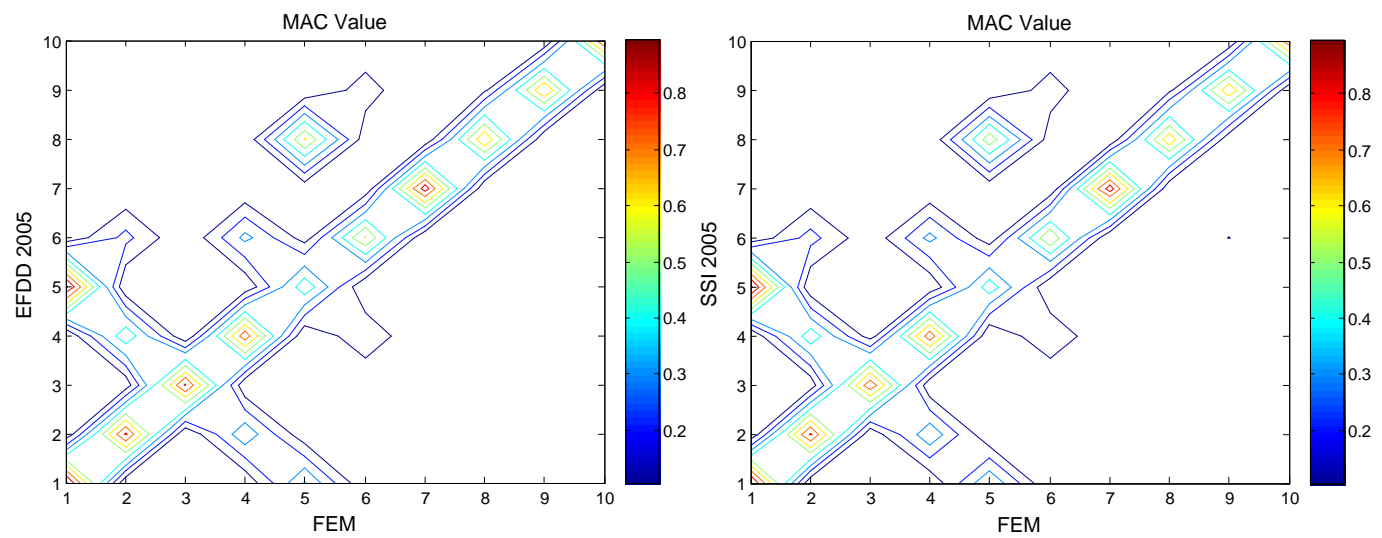

(a) MAC Matrix between EFDD and (b) MAC Matrix between SSI and FEM FEM

Fig. 14. MAC Matrix between experimental and numerical results. 


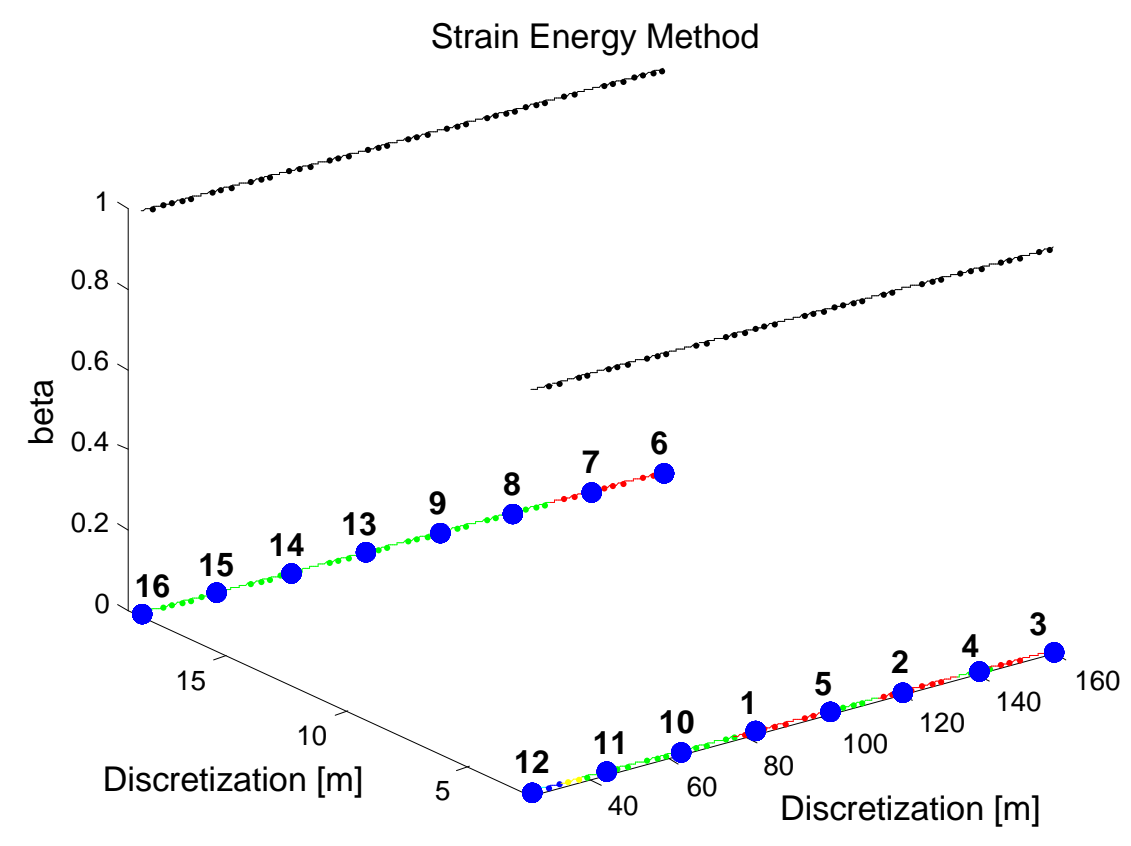

Fig. 15. Strain Energy Method. 
Table 1: Natural frequencies. Fluid traffic conditions.

\begin{tabular}{|c|c|c|c|c|c|c|}
\hline$f_{P P}[\mathrm{~Hz}]$ & $f_{A N P S D_{s}}[\mathrm{~Hz}]$ & $f_{E F D D}[\mathrm{~Hz}]^{1}$ & $f_{E F D D}[\mathrm{~Hz}]^{2}$ & $f_{S S I}[\mathrm{~Hz}]^{3}$ & $f_{S S I}[\mathrm{~Hz}]^{4}$ & $f_{F E M}[\mathrm{~Hz}]$ \\
\hline 0.75 & 0.75 & 0.7273 & 0.7271 & 0.7252 & 0.7283 & 0.751662 \\
\hline 1.25 & 1.25 & 1.232 & 1.236 & 1.228 & 1.24 & 1.11 \\
\hline 2.05 & 2.05 & 2.03 & 2.036 & 2.03 & 2.032 & 2.002 \\
\hline- & - & 2.032 & 2.044 & 2.033 & 2.034 & 2.144 \\
\hline 2.5 & 2.5 & 2.49 & 2.495 & 2.492 & 2.509 & 2.066 \\
\hline 3.45 & 3.45 & 3.456 & 3.471 & 3.447 & 3.469 & 3.234 \\
\hline 3.9 & 3.9 & 3.895 & 3.908 & 3.904 & 3.908 & 3.817 \\
\hline 4.5 & 4.5 & 4.485 & 4.493 & 4.471 & 4.484 & 5.054 \\
\hline 5.35 & 5.35 & 5.348 & 5.351 & 5.339 & 5.344 & 6.871 \\
\hline 5.8 & 5.85 & 5.833 & 5.824 & 5.822 & 5.806 & 5.509 \\
\hline
\end{tabular}

1 Test carried out in 2005

2 Test carried out in 2006

3 Test carried out in 2005

4 Test carried out in 2006 
Table 2: Natural frequencies. Traffic jam on the bridge.

\begin{tabular}{|c|c|c|c|c|c|c|}
\hline$f_{P P}[\mathrm{~Hz}]$ & $f_{A N P S D_{s}}[\mathrm{~Hz}]$ & $f_{E F D D}[\mathrm{~Hz}]^{5}$ & $f_{E F D D}[\mathrm{~Hz}]^{6}$ & $f_{S S I}[\mathrm{~Hz}]^{7}$ & $f_{S S I}[\mathrm{~Hz}]^{8}$ & $f_{F E M}[H z]$ \\
\hline 0.75 & 0.7 & 0.7182 & 0.7144 & 0.7084 & 0.7022 & 0.74214 \\
\hline 1.25 & 1.2 & 1.208 & 1.2 & 1.236 & 1.206 & 1.0777 \\
\hline 2.05 & 2 & 1.992 & 1.994 & 2.001 & 1.982 & 1.903 \\
\hline- & - & 2.019 & 2.013 & 2.013 & 2.035 & 2.1085 \\
\hline 2.5 & 2.5 & 2.474 & 2.464 & 2.485 & 2.467 & 2.004 \\
\hline 3.45 & 3.45 & 3.453 & 3.476 & 3.45 & 3.438 & 3.105 \\
\hline 3.9 & 3.9 & 3.914 & 3.931 & 3.905 & 3.933 & 3.619 \\
\hline 4.5 & 4.5 & 4.508 & 4.543 & 4.494 & 4.52 & 4.762 \\
\hline 5.35 & 5.35 & 5.361 & 5.363 & 5.352 & 5.361 & 6.76 \\
\hline 5.8 & 5.8 & 5.832 & 5.873 & 5.829 & 5.89 & 5.256 \\
\hline
\end{tabular}

5 Test carried out in 2005

6 Test carried out in 2006

7 Test carried out in 2005

8 Test carried out in 2006 
Table 3: Damping ratios. Fluid traffic conditions.

\begin{tabular}{|c|c|c|c|}
\hline$\xi_{E F D D}[\%]^{9}$ & $\xi_{E F D D}[\%]^{10}$ & $\xi_{S S I}[\%]^{11}$ & $\xi_{S S I}[\%]^{12}$ \\
\hline 1.032 & 1.756 & 2.398 & 2.567 \\
\hline 0.7081 & 1.216 & 1.151 & 1.137 \\
\hline 0.4778 & 0.9575 & 1.346 & 1.809 \\
\hline 1.211 & 1.135 & 0.7607 & 1.152 \\
\hline 0.5717 & 0.9463 & 0.7641 & 1.078 \\
\hline 0.8789 & 0.7017 & 0.7287 & 0.9164 \\
\hline 0.3202 & 0.8016 & 0.6447 & 0.7219 \\
\hline 0.4263 & 0.7968 & 0.6404 & 1.014 \\
\hline 1.065 & 1.055 & 0.9012 & 1.067 \\
\hline 1.137 & 1.092 & 0.9462 & 1.765 \\
\hline
\end{tabular}

9 Test carried out in 2005

10 Test carried out in 2006

11 Test carried out in 2005

12 Test carried out in 2006 
Table 4: Damping ratios. Traffic jam on the bridge.

\begin{tabular}{|c|c|c|c|}
\hline$\xi_{E F D D}[\%]^{13}$ & $\xi_{E F D D}[\%]^{14}$ & $\xi_{S S I}[\%]^{15}$ & $\xi_{S S I}[\%]^{16}$ \\
\hline 1.178 & 2.196 & 2.26 & 3.527 \\
\hline 1.748 & 2.266 & 4.119 & 2.054 \\
\hline 1.663 & 2.629 & 1.665 & 2.601 \\
\hline 2.674 & 2.843 & 2.053 & 3.132 \\
\hline 0.809 & 1.434 & 1.296 & 1.117 \\
\hline 1.161 & 1.183 & 1.703 & 2.667 \\
\hline 1.272 & 2.8 & 1.48 & 2.58 \\
\hline 1.208 & 1.583 & 1.76 & 2.459 \\
\hline 1.186 & 1.515 & 1.185 & 1.503 \\
\hline 1.462 & 1.302 & 2.048 & 1.498 \\
\hline
\end{tabular}

\footnotetext{
$\overline{13}$ Test carried out in 2005

14 Test carried out in 2006

15 Test carried out in 2005

16 Test carried out in 2006
} 